\title{
Community-Based Participatory Research a Low-Income Setting: An Illustrative Case of Study
}

\author{
Sandy Lazarus \\ Naiema Taliep \\ Medical Research Council, South Africa \\ University of South Africa, South Africa
}

\author{
Abdulsamed Bulbulia \\ University of South Africa, South Africa \\ Shaun Phillips \\ Hearts of Men, Cape Town \\ Mohamed Seedat \\ University of South Africa, South Africa \\ Medical Research Council, South Africa
}

Address correspondence to Sandy Lazarus, University of South Africa-Medical Research Council Safety and Peace Promotion Research Unit, PO Box 19070, Tygerberg, 7505, South Africa. Email: slazarus@uwc.ac.za

This article describes a community-based participatory research (CBPR) approach in a low-income setting. Using the SCRATCHMAPS project as a case example and with literature control, we show that CBPR is influenced by dynamics relating to knowledge and power, resources and power, participation and power, as well as community dynamics and research methodology. We conclude that the CBPR approach offers a number of opportunities to conduct rigorous and trustworthy research and to contribute to individual and community development, despite associated difficulties.

Keywords: community engagement, community-based participatory research (CBPR), possibilities and challenges, Western Cape, South Africa

Community-based participatory research (CBPR) as an approach to research constitutes a worldview, and therefore an approach to conducting research (Israel, Eng, Schulz, \& Parker, 2005). This approach to research is congruent with a participatory paradigm (Guba \& Lincoln, 2005), which reflects a worldview that is holistic, systemic, and relational in nature, and where knowledge is generated by partners within a critical perspective.

The following values and principles of CBPR, which guide the SCRATCHMAPS project, have been noted by experts in the field (Hawe, Shiell, \& Riley, 2009; Israel, Schulz, Parker, \& Becker, 2001; Israel et al., 2005; Lazarus, Duran, Caldwell, \& Bulbulia, 2012; Minkler \& Wallerstein, 2008; Schulz et al., 2002; Wallerstein \& Duran, 2008): the 'community' is the unit of focus; community engagement occurs at all levels of the research process; the research is relevant to the community; it builds on the strengths and resources of the community; there is a commitment to action research, which emphasises a dynamic relationship between theory and practice (praxis); it is based on a partnership between the research institutions and community members; it promotes co-learning and mutual benefits, including the sharing of findings and knowledge (including indigenous knowledge systems) with all relevant stakeholders; and it is a long-term process, with commitment to ownership and sustainability.
This approach to research has been directly linked to community engagement (Nation, Bess, Voight, Perkins, \& Juarez, 2011). Within universities, community engagement is an umbrella term which includes various professional and academic activities pursued in partnership with local communities, including service-learning, professional service, community-based research, and applied research. Such enactments include the following key characteristics: understanding and respecting the historical and current dynamics of the community; aligning community engagement with the community's own agendas; establishing appropriate and accountable structures and processes to include relevant and diverse participation; fostering engagement through optimal participation and community ownership throughout the process; and strengthening and sustaining communities (Attree \& French, 2007; Herbertson, Ballesteros, Goodland, \& Munilla, 2009; Lazarus et al., 2012; Popay, 2006; Rifkin, Lewando-Hundt, \& Draper, 2000).

The following benefits of CBPR as a form of community engagement have been noted by Lazarus et al. (2012): CBPR acknowledges power dynamics and fosters democratic practices; benefits knowledge development, particularly through the acknowledgement and integration of local community-embedded knowledges; supports local capacity building; and responds to real needs, resulting in sustainable community development. Minkler and Baden (2008) argue that, in addition to positive community development principles, CBPR results in more ef- 
fective research. It supports both external and internal validity because people are likely to be more honest and willing to participate, and CBPR methods contribute to better translation of research and practice by facilitating community-academic communication and flows of knowledge.

\section{The Study Context}

This study has been motivated by the fact that violence is an important public health and social issue in South Africa, with homicide continuing to be a leading cause of premature death for both males and females in South Africa (Donson, 2008; Krug, Dahlberg, Mercy, Zwi, \& Lozano, 2002). Males are particularly at risk of being both perpetrators and victims of violence, having the highest reported injury-related mortality rates in the world (Krug et al., 2002; Lazarus et al., 2011), with 6.5 male violence-related deaths for every female violence-related death being recorded in South Africa (Donson, 2008). Religion and spirituality are unexplored resources for violence prevention and safety and peace promotion (Laher, 2008; Lazarus, Seedat, \& Naidoo, 2009). Religious assets refer to locally embedded religious images, values, practices, people and organisations, leveraged through local and translocal agency, which can result in action to promote safety and peace. Crucially, these assets are both tangible (e.g., a mosque) and intangible (e.g., compassion), and the relation between these two aspects makes an important contribution to understanding them. Spiritual capacity, a vital dimension of intangible assets, comes from the energy and creative freedom that allow human beings to act with generative (life-giving) resilience, mindfulness, dignity and hope for a whole and fulfilled life (Cochrane et al., 2012).

\section{Goals for the Study}

The main research question guiding the SCRATCHMAPS project, which is the illustrative case example discussed in this article, is: how can the mobilisation and leveraging of community assets, with a particular focus on spiritual capacity and religious assets, promote safety and peace, through the promotion of positive masculinities, in selected communities in South Africa and the United States of America? The overall objectives of this research are (1) to develop conceptual and theoretical frameworks to understand the possible mediating influences of spiritual capacity and religious assets in the promotion of safety and peace, particularly in relation to the supporting of positive masculinities; (2) to identify spiritual capacity and religious assets in local communities, and to understand the processes and dynamics by which they work; (3) to develop, implement and evaluate an intervention that mobilises spiritual capacity and religious assets to promote safety and peace, with a particular focus on encouraging positive masculinities; and (4) to contribute to the knowledge-base and practical understanding of community engagement as it is expressed through a community-based participatory research (CBPR) approach. The main aim of the intervention (which does not constitute a focus for this article) is to promote the construction of non-violent, pro-social masculine identities (Barker \& Ricardo, 2005; Lazarus, Tonsing, Ratele, \& Van Niekerk, 2011; Ratele \& Suffla, 2010).

This article focuses on some possibilities and challenges associated with enacting community engagement within a community-based participatory research (CBPR) approach, with the aim of contributing to both theoretical debate and practical enhancement of community-engaged research. We draw on our experiences in the Spiritual Capacity and Religious Assets for Transforming Community Health by Mobilising Males for Peace and Safety (SCRATCHMAPS) project, which is located in a low-income peri-urban community in the Western Cape ${ }^{1}$. This project falls under the broader Ukuphepha Safety, Peace and Health Programme of the University of South Africa-Medical Research Council Safety and Peace Promotion Research Unit (SAPPRU). The Ukuphepha Programme is centred on the development and evaluation of community interventions in a number of geographical catchment areas in South Africa.

\section{Method}

\section{Participants and Setting}

This discussion of CBPR as a form of community engagement focuses on a particular community, which is situated within the Helderberg Basin in the province of the Western Cape in South Africa. There are roughly 164 houses and approximately twice as many backyard dwellings within this relatively small community. The bulk of the residents is Afrikaans speaking, and were previously categorised as 'coloured' ${ }^{2}$ by the apartheid regime; and the majority appear to adhere to the Christian faith. Previous general population estimates from the Development Action Group (1997) indicate that $47.8 \%$ of the population is male and that more than half the residents $(81.2 \%)$ are younger than forty years of age. Statistics also show a high percentage $(45 \%)$ of low educational levels, with almost half of the population earning less than R1000 per month. There have been a few development interventions in this community, including the construction of housing and social service for children and adults living on the streets. However, initiatives are scattered and fragmented.

\section{Procedure and Data Collection}

In order to achieve the objectives of the study, a community case-study, multi-method design, using both qualitative and quantitative methods, is being pursued. The overall research design (covering the period 2011 to 2015) incorporates four main phases: phase one focuses on initial community engagement and preparation; phase two includes the planning and implementation of the intervention; phase three focuses on outcomes evaluations; and phase four focuses on the consolidation of the conceptual framework, comparative analyses and sharing of findings, as well as on the sustainability on the intervention in the local community. Two aspects which run across all four phases are (a) process and outcomes evaluations, and (b) the development of a conceptual and theoretical framework.

This project commenced with a process of identifying all key sectors relevant to the focus of the project, and community development more broadly speaking. These sectors were then invited to attend the first community stakeholders' meeting. Approximately 30 stakeholders attended this meeting in May 2011 , with the community supporting the establishment of two structures to facilitate community participation: the SCRATCHMAPS advisory committee and the research team. The advisory committee comprises about 27 local community members who represent key sectors from the community. This includes: health, education, police, community safety, justice, correctional services, social development, and faith-based and non-governmental organisations (NGOs), including a well-known and respected NGO that works directly with men namely, Hearts of Men. The advisory committee has met monthly since July 2011. 
The research team members were recruited through public processes, including household pamphlet drops and posters distributed in the community. Of the 18 local community members who formally applied (submitting letters and CVs), 10 were selected by a panel of the advisory committee. The number of community researchers was determined by the advisory committee, based on information on the research team's tasks and the overall budget available from the University of South Africa, a partner on SAPPRU. These ten members are all from the local community, and reflect a combination of youth and 'experience'. All of them are unemployed.

\section{Community Engagement Strategy}

The community engagement strategy pursued in this project thus far has included: (1) an initial walkabout by the academic researchers, guided by a community leader; (2) the community meeting attended by key stakeholders; (3) the establishment of the SCRATCHMAPS advisory committee; (4) the establishment of the SCRATCHMAPS research team, and (5) a second community meeting, prior to initial base-line data collection. Community engagement is planned as an ongoing process, operationalised primarily through (a) monthly advisory committee meetings, (b) regular research team meetings and workshops, (c) community asset mapping and other participatory research methods in the community, (d) general community meetings, and (e) community pamphlets and briefs. SCRATCHMAPS conceptualises community geographically, with the identified geographical region constituting a focus for the research and community development. All members of this community, and local and translocal service providers, are invited to participate in the research and action interventions.

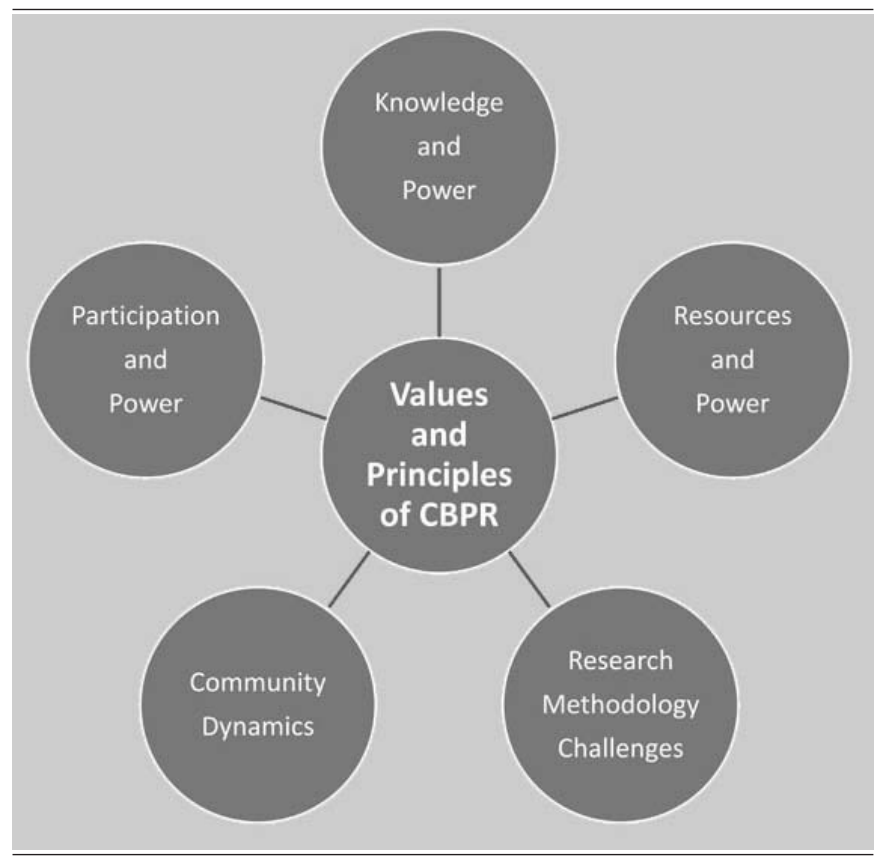

Figure 1. Framework for reflections

\section{Findings}

\section{Possibilities and Challenges Associated with Enacting Community Engagement}

In this section we focus particularly on the strategies used to address challenges we encountered within the SCRATCHMAPS project. The framework used to guide the reflections is informed by Lazarus and her colleagues (2012) who drew on their collective experiences in historically oppressed communities in South Africa and the USA to identify successes and challenges experienced in conducting CBPR. They organised the main challenges according to the following categories: knowledge and power; resources and power; participation and power; community dynamics; and research methodology. All these challenges are directly linked to the principles of CBPR outlined in the introduction.

A review of relevant literature reveals that a range of strategies have been employed to overcome the challenges highlighted in Figure 1 above (Bradbury \& Reason, 2008; Farquhar \& Wing, 2008; Flicker, Travers, Guta, McDonald \& Meagher 2008; Mertens, 2005; Minkler \& Baden, 2008; Springett \& Wallerstein, 2008). These include the following general community development strategies: ensuring that attention is paid to community needs and agendas; developing and utilising participatory leadership skills; facilitating optimal participation throughout the research process; and working within a strict ethical code of conduct, and ensuring sensitivity to local cultural norms. Within the context of these development guidelines, other research strategies include: balancing research tensions (for example, control of phenomena); developing rigorous tools and techniques; using local and culturally appropriate methods and instruments, including community input in the development phases of both instruments and methods; using multiple methods; developing various validity measures to ensure rigour and quality; including community members in the data analysis and interpretation where appropriate; disseminating the research findings in languages and formats appropriate to the community; and focusing on how the action emanating from the research will be pursued.

Using the framework identified by Lazarus et al. (2012), the ensuing discussion will focus on challenges experienced within SCRATCHMAPS, and strategies employed thus far to overcome them.

\section{Knowledge and Power}

Our reflections on knowledge and power will focus on three sub-themes identified by Lazarus et al. (2012), namely different interests, power-differentials, and respecting knowledge systems.

Different interests. Springett and Wallerstein (2008) note the importance of paying attention to the community's needs and agendas. Nation et al. (2011, p. 94) reiterate this point, stating that it is important to "build a research agenda that reflects the collective interests of our partnership and is perceived as relevant by the community." The SCRATCHMAPS project has been accepted within the local community, as it meets the felt needs of the stakeholders, particularly with its focus on community development, and promoting positive masculinities more specifically.

The acceptance of the project was facilitated by key stakeholders at the beginning of the process, and more specifically within the advisory committee. However, it is probable that different interests will emerge during the process of developing the 
intervention focusing on the promotion of positive masculinities. The project has allowed for maximum participation of the community in the identification, planning and implementation of the intervention, and will endeavour to attend to different interests as they arise. Despite the general acceptance of the project in the initial stages, we are aware that community assertion of interests has been limited, primarily as a result of the academic institutions' initiation of the project; their funding of the work; their time-on-task in the management of the project; and the fact that the overall design has been linked to a doctoral study which has had to be approved by university ethics and research committees.

Power-differentials. Nation et al. (2011) reflect specifically on power differentials within a community-engaged research partnership. They illustrate how power sharing among partners relating to research objectives, administrative decision-making, and data analysis and feedback differentiate levels of engagement. Springett and Wallerstein (2008) also discuss the power relationship between researcher and researched, which, they argue, presents a number of problems. It is important to note that CBPR reflects the values of a participatory research paradigm (Guba \& Lincoln, 2005) and therefore centralises challenges relating to power relations and decolonisation of knowledge (Bishop, 2005; Smith, 2005).

The balance of power is definitely in the hands of the academic staff in SCRATCHMAPS at the moment, in part because of their access to scientific knowledge and processes relating to the project. In an attempt to acknowledge this power differential, the academic researchers share relevant scientific knowledge in various ways, including the use of a variety of formats for presenting information and knowledge. Attempts are made to present this knowledge in accessible ways, with a particular sensitivity to academic and discipline-specific terminology. More work needs to be done in this area, however, as the researchers have to continually reflect on their language usage. Every effort is made to communicate knowledge and information by means of the mother tongue of the community members, which in this case is predominantly Afrikaans.

Respecting knowledge systems. Attempts are constantly made to engage with community-embedded knowledges in this project. One way in which this is pursued is through grounded theory development relating to the key concepts of the study, that is, peace, safety, spiritual capacity and religious assets, and positive masculinities, pursued through interactive research methodologies. In addition to various exercises pursued within an asset mapping approach, photovoice is one of the methods used to elicit community perspectives. This refers to a participatory method of research that combines photography, critical dialogue and social action, facilitates expression of the voices of the community through use of visual representation and narratives. Furthermore, the local community will be closely involved in the development of the intervention. This includes local organisations that are working with men, and a project that focuses on reclaiming indigenous Khoi cultural histories and identities. Whether these strategies constitute real engagement with community-embedded knowledge systems will depend on the extent to which authentic co-learning and co-creation of knowledge is pursued throughout the life of the project.

\section{Resources and Power}

In this next category of challenges, two key themes are used to organise our reflections: financial inequalities, and donors' interests and frameworks (Lazarus et al., 2012).
Financial inequalities. Nation et al. (2011) and others have highlighted the importance of understanding the role of money in community research projects, and in particular how it can inadvertently create conflict. Factors to consider include who has the money, how it is used, and how it is managed. Money is held, managed and controlled by the University of South Africa and the Medical Research Council within which SCRATCHMAPS are located. Although this has not been raised as an issue by community members, it could constitute a continuing 'unbalancing' factor in the power dynamics in the project. One way of correcting this imbalance, at least partially, has been to make the budget 'visible' or transparent within the SCRATCHMAPS structures through the regular presentation of accessible verbal and written financial statements. This has not been a straightforward process, however, as academic structures do not usually adopt this practice, and concerns have been expressed regarding the possible conflict dynamics that could be created through sharing the budget on paper. In this project, however, we have chosen to prevent possible conflicts through ongoing negotiations concerning all budget items, such as researcher wages (set by the university, and therefore seen as 'fair'), and food and venue expenses. We try to support the financial development of community members through the project by providing wages for the community researchers, and through paying local people for food and the use of venues. We also issue certificates of completion and participation in all training events, which can be listed on personal CVs. In a small way, this project is therefore contributing to both skills and knowledge development and temporary employment.

Donors' interests and frameworks. Springett and Wallerstein (2008) emphasise that CBPR often involves a great deal of time and resources, which need to be built into research protocols and funding grants. They also note that funders are hesitant to support unpredictable processes and outcomes. While the research institutions supporting SCRATCHMAPS are generous in their approach, there are factors with the potential to create problems, as donor frameworks are not always sensitive to community needs. The 'visible budget' strategy mentioned above is one of these factors. Others are the time-frames and procedures for payments, which are complex and often take too long for people needing to be paid quickly and regularly. This is particularly important for seasonally employed community members who act as community researchers in the project. Attempts have been made to prevent these types of problems in SCRATCHMAPS, including negotiating with the institutions concerned, and ensuring that the administration of claims and payments are dealt with as efficiently as possible. The negotiations include eliciting the views of the community researchers on their own needs, and then attempting to meet those needs through official channels. This has resulted in their receiving payments on a monthly basis. Financial accountability has been ensured through rigorous accounting procedures pursued by the main researchers in the project.

\section{Participation and Power}

The relationship between the various stakeholders, academics and community members is central to the issue of power and participation (Nation et al., 2011). Thus, strategies to support effective collaboration and equitable power relations are particularly important, and every effort needs to be made to promote participation within a commitment to co-learning and co-creating. 
Using the framework of challenges identified by Lazarus et al. (2012), we reflect specifically on the following sub-themes: whose research agenda is on the table, and what are the key challenges relating to facilitating optimal participation within the research process? Several strategies that have been used to find answers to these questions (see Bradbury \& Reason, 2008; Farquhar \& Wing, 2008; Flicker et al., 2008; Mertens, 2005; Minkler \& Baden, 2008; Nation et al., 2011; Springett \& Wallerstein, 2008) are included.

Whose research agenda? Nation et al. (2011) argue that power relations are influenced by 'who initiates': the community or the researcher(s). Drawing on their experiences of community-engaged research, they argue that the structural dynamics that arise during the initial establishment of the research partnership can influence the relevance and usefulness of the research.

The SCRATCHMAPS project was initiated by the SAPPRU and accepted by the community stakeholders. A broad proposal was presented at the first community stakeholders' meeting, and thereafter presented and debated repeatedly (over a period of six months) within the advisory committee, and later the research team. Details regarding actual questions posed, research methods and instruments used, and the eventual intervention developed, are currently being developed within that framework. This reflects a practical commitment to co-learning and co-creating. It is expected that while some aspects will remain, many changes will be made to ensure that the research is relevant and appropriate to both the aims of the research and the needs of the community. To foster collective ownership, we encourage the advisory committee and research team members to constantly play an active role in setting agendas and sharing leadership in the project.

Facilitating participation. Springett and Wallerstein (2008) have noted the following particular difficulties relating to participation. First, researchers often lack all the skills required to conduct research within a CBPR framework. Second, the wider the reach of a project, the more difficult it is to ensure a democratic process. Third, it is difficult to control the 'coming and going' of people in the project.

In SCRATCHMAPS, structures have been put in place for ongoing optimal participation, primarily through the advisory committee and the research team. The advisory committee is the management committee of this project, and therefore the body to which academic and community researchers are accountable. This is one step in moving towards genuine shared control. Nation et al. (2011) highlight the importance of creating such an accountability structure to balance the power differentials in participatory research.

The process is driven from the academic research team, but e-mail, telephonic and face-to-face communication is constant. All processes followed by both academic and community members are captured in meeting notes or minutes, which are regularly distributed among advisory committee and research team members. Meetings are chaired and guided in an optimally participative way, with the research and community leaders all being experienced in group dynamics and facilitation. Participation is enhanced by the enthusiasm expressed by the academic leaders and members of the advisory committee and research team, and interactive workshop-style exercises are often used to facilitate participation. Group facilitation, and workshop and project management skills are shared through the two SCRATCHMAPS structures. Participation is also facilitated by the fact that members of the two structures know one another well. This factor does, however, create a challenge in that the dynamics are affected by the presence of people who historically have had a dominant role in the community. This is one of many dynamics requiring constant attention within our group facilitation process.

Reflexivity challenges. A critical or emancipatory approach to research includes the need to be reflexive, with a particular focus on power relations (Nation et al., 2011). The academic research team members in SCRATCHMAPS are aware of the need for reflexivity and make concrete efforts to maintain this reflection especially about matters related to participation and power dynamics. One of the ways in which we do this is through diary reflections (see Ortlipp, 2008), where we record their experiences and reflections on a regular basis. This principle and process is being embedded within the project's local structures; thus the community researchers also keep their own diaries. This process of reflexivity is guided by a set of criteria linked to both the aims and implementation of the study. Hence, following Nation et al. (2011), SCRATCHMAPS attempts to establish a norm or structural mechanism in order to support reflective practice.

\section{Community Dynamics}

In this category of analysis, the following sub-themes guide our reflections on SCRATCHMAPS: political dynamics, cultural diversity, community empowerment, and the challenge of sustainability (see Lazarus et al., 2012).

Political dynamics: Political dynamics always exert an influence in participatory research. We are aware of the formal political dynamics in the community, but this aspect has been minimised by the common purpose that brings everyone together. It is often a project such as this that creates a 'safe' space for people to work together across these differences. Historical dynamics are also evident in this project. In particular, the effects of our apartheid history continue to play themselves out, particularly in relation to how we see ourselves and our power in the situation. The need for a decolonising approach to research is therefore relevant in this context (Bishop, 2005; Smith, 2005). The local community history is also a living dynamic, as many of the members of the advisory committee have a long-standing history in the community, with some occupying influential positions. This is both an asset and a potential challenge in this research, as we have to ensure that the historical interpersonal power dynamics do not confound the research process, from both an implementation and data quality point of view.

Cultural diversity. The SCRATCHMAPS local community in the Western Cape is primarily homogeneous in terms of past racial categories, and most are Afrikaans speaking and working class in social status. We do not yet have a full profile of the religious or spiritual affiliations or practices of members of this community, but it appears that the majority are Christian in orientation. We do have members of the Muslim and Rastafarian faiths in SCRATCHMAPS structures, but we are not aware of the extent of these faiths in the community at large. What is important to note is that despite the apparent homogeneity of this community population, there are differences which need to be accommodated, valued and drawn upon. This is important given the strengths-based focus of SCRATCHMAPS. It is interesting to note that at the first research team training session, held in November 2011, participants identified the need for conflict management and resolution training. The need to accommodate different religious beliefs and practices in particular was highlighted. In addition, the demands of both teamwork and 
community development require a high level of skill in the area of conflict management. This area has therefore been included as a central component of ongoing capacity development.

Community ownership and sustainability. Nation et al. (2011), reflecting on their experiences of community engaged violence prevention research in Nashville, argue that the success of this type of project is determined by the extent to which the intervention is owned by the community. The concept of ownership is often loosely used, and minimally debated. In practice, ownership needs to be pursued through the use of optimal participation strategies, and the promotion of multilateral transfer of capacities. Strategies to support community development and ensure sustainability must also be built into the project planning, and pursued accordingly, including collective debate and understanding within the project structures.

In resonance with such strategies to promote sustainability, every opportunity to share skills and knowledge among partners is pursued in this project, including training in areas that contribute directly and indirectly to personal and professional development, and future employment opportunities. Skills and knowledge are shared informally 'on the job', but also through formal training sessions. An ongoing challenge in this process is to ensure that this exchange of skills and knowledge is guided by the principles of co-learning and co-creating, to ensure a genuine multilateral transfer of capacities.

Although SCRATCHMAPS has made some provision for sustainability, primarily through following a full reflect-planact-evaluate process of intervening, further collective reflection and planning is required in this regard.

\section{Methodological Challenges}

It is important to note that there are a number of tensions inherent in the CBPR approach to research. These tensions are reflected in (a) the pursuit of science/research goals versus the pursuit of practical/action goals, and (b) the need for contro over phenomena versus the call for maximum collaboration. In this type of community research, people cannot be randomly assigned; the research often cannot be replicated, as no two communities are the same; disparities in programmes means that findings cannot be generalised; external events create bias; and uncontrollability is exacerbated if there is too much community choice across sites (Farquhar \& Wing, 2008: Heller et al., 1984; Nation et al., 2011; Springett \& Wallerstein, 2008; Stoeker, 2005). Furthermore, validity remains an area of contestation, although many researchers have found ways to overcome these concerns (e.g., Bradbury \& Reason, 2008; Mertens, 2005; Reason \& Bradbury, 2008).

Using the sub-categories identified by Lazarus et al. (2012), this section focuses on: control and validity challenges, living in the 'messiness', time-frame challenges, and challenges relating to research translation.

Control and validity challenges. It is clear that CBPR raises difficulties relating to obtaining scientific 'control' for research purposes. Our experience in SCRATCHMAPS supports this. In particular, we have had to debate and make choices about our research design to ensure that we accommodate these challenges. The choice of a community case-study, multi-method design emerged out of a broader consideration of various designs. The community case-study design was chosen because of its focus on depth, and also because it easily allows for flexibility. Within the research environment, we are satisfying all the 'quality' requirements, including some of the traditional 'validity' concerns, through ensuring that we conduct all the data collection and analyses methods with rigour.

Living in the 'messiness'. Our collective experience supports the view that CBPR research is 'messy'. The challenge is therefore to manage the messiness. First, personal development is key, as researchers (and funders) have to learn to be flexible, and be able to manage conflict (Nation et al., 2011). Conflict management and resolution training is therefore included in the research training process in SCRATCHMAPS. Second, although the 'messiness' may result in a shift in the research objectives and/or design, for the purposes of accommodating contextual realities it is important to note that this does not have to compromise the integrity of the study. In fact, shifts motivated by authentic community concerns and contexts help to ensure the relevance of the research, one of the principles of CBPR. As SCRATCHMAPS is focusing particularly on process evaluation, any shifts and the dynamics influencing the shifts are being captured and analysed in depth.

Time-frame challenges. This type of research takes longer. To accommodate this, the SCRATCHMAPS research proposal and budget has built in all relevant aspects, over a realistic period of time. However, one key challenge in this regard is the commitment to the 'action' aspects of a CBPR project. Donors and research institutions are often very cautious about committing themselves to any action that does not include a clear research component. While this is understandable, it creates a significant barrier in the process of building trust with the community concerned, and often results in a lack of sustainability. In the case of SCRATCHMAPS, the challenge of ensuring the realisation of the 'action' component of the project is partially overcome by the constant support of the academic researchers in the planning, intervention and evaluation of the male-focused intervention. Other forms of supporting community action are being considered within a 'sustainability' programme, currently under consideration within the advisory committee.

From research to action (research translation). Nation et al. (2011) argue that the extent to which 'action' will be owned and pursued by the community is determined early on in the formation of the partnership. This aspect therefore needs to be a major focus in the early stages of project negotiation and development. This includes agreeing upon the role of academic researchers in community action, to avoid the development of expectations that cannot be met.

While there are many strategies that can be used in the area of research translation, using a CBPR approach in itself facilitates a broad framework to ensure translation. Research translation occurs through the actual research process, and through the product(s) of the project. In the evaluation of the SCRATCHMAPS project, we are focusing specifically on the research process, including examining how the research translates into community development action.

\section{Discussion and Conclusion}

Nation et al. (2011) identify community initiation and community collaboration as distinct approaches to community-engaged violence prevention research, with the method of power sharing among partners being a central factor distinguishing different levels of engagement. Both community initiation and community collaboration approaches are linked to different meta-theoretical paradigms: a 'practical' or pragmatic paradigm on the one hand, and an 'emancipatory' or critical paradigm on 
the other. While a practical approach to community-engaged research focuses primarily on finding common ground between stakeholders, the emancipatory approach encourages examination of power differences between stakeholders, with a particular emphasis on democratising knowledge and resisting any form of exclusion and oppression. Both perspectives require high degrees of participation, but the difference lies primarily in who initiates and controls the research. Nation et al. (2011) argue that a community initiated approach, which reflects a practical paradigm, is initiated and driven by a group or the community, with the researcher(s) playing a supportive role. In a community collaboration initiative, the researchers usually initiate the research, seek out groups with whom to partner, and play a leading role in the development of interventions. The SCRATCHMAPS project has adopted a mixed stance, combining both community-initiated and collaborative approaches. This is evident in the leading role of the academic researchers in the project management. The academic researchers are open to negotiating the research design and related research processes, use community structures to manage the project, and, most important, encourage the community to develop a 'home-grown' intervention (Nation et al., 2011).

Our article focuses on the fourth objective of the SCRATCHMAPS project, namely to contribute to the knowledge-base and practical understanding of community engagement as it is expressed through a community-based participatory research (CBPR) approach. The findings are presented in the context of the following main categories of challenges in CBPR: knowledge and power, resources and power, participation and power, community dynamics, and research methodology. Although the framework focuses on challenges, many successes and opportunities experienced in the SCRATCHMAPS project are highlighted in this discussion.

Relevant literature, and the experiences of the authors, suggests that CBPR does provide a strategy or framework for promoting effective community engagement between academic and community role players. We believe that the indicated challenges can be overcome if the basic principles of community development and empowerment are upheld and pursued, and a focus on the key principles of co-learning and co-construction of both knowledge and action, within a framework of genuine partnership, maintained. CBPR, as a form of research, takes seriously the power relations within research initiatives, and genuinely tries to honour the communities concerned.

\section{References}

Attree, P., \& French, B. (2007). Testing theories of change associated with community engagement in health improvement and health inequalities reduction. Report prepared for National Institute for Health and Clinical Excellence (NICE). Retrieved October 24, 2011, from p.attree@lancaster.ac.uk

Barker, G., \& Ricardo, C. (2005). Young men and the construction of masculinity in sub-Saharan Africa: Implications for HIV/AIDS, conflict, and violence. Social Development Papers: Conflict Prevention \& Reconstruction, Paper No. 26. Washington, DC: The World Bank.

Bishop, R. (2005). Freeing ourselves from neocolonial domination in research: A Kaupapa Maori approach to creating knowledge. In N. K. Denzin \& Y. S. Lincoln (Eds.), The Sage handbook of qualitative research (3rd ed., pp. 109-239). Thousand Oaks, CA: Sage.
Bradbury, H., \& Reason, P. (2008). Issues and choice points for improving the quality of action research. In M. Minkler \& N. Wallerstein (Eds.), Community-based participatory research for health: From process to outcomes (pp. 425-444). San Francisco, CA: Jossey-Bass.

Cochrane, J., Lazarus, S., Suffla, S., Ratele, K., Schochet, I., Taliep, N., \& Seedat, M. (2012). SCRATCHMAPS conceptual framework: A position paper. Unpublished manuscript, SCRATCHMAPS Conceptual Working Group, International Religious Health Assets Programme (IRHAP) UCT \& MRC-UNISA SAPPRU, Cape Town, South Africa.

Development Action Group. (1997). Homes for all: A Development Action Group case study of the housing programme in Cassablanca and Erijaville. Cape Town, South Africa: Development Action Group.

Donson, H. (2008). A profile of fatal injuries in South Africa 2007. Tygerberg, South Africa: Medical Research Council-University of South Africa Crime, Violence and Injury Lead Programme.

Farquhar, S. A., \& Wing, S. (2008). Methodological and ethical considerations in community-driven environmental justice research. In M. Minkler \& N. Wallerstein (Eds.), Community-based participatory research for health: From process to outcomes (pp. 263-283). San Francisco, CA: Jossey-Bass.

Flicker, S., Travers, R., Guta, A., McDonald, S., \& Meagher, A. (2008). Ethical review of community-based participatory research: Considerations for institutional review boards. In M. Minkler \& N. Wallerstein (Eds.), Community-based participatory research for health: From process to outcomes (pp. 435-440). San Francisco, CA: Jossey-Bass.

Guba, E. G., \& Lincoln, Y. S. (2005). Paradigmatic controversies, contradictions, and emerging confluences. In N. K. Denzin \& Y. S. Lincoln (Eds.), The Sage Handbook of Qualitative Research (3rd ed., pp. 1-32). Thousand Oaks, CA: Sage.

Hawe, P., Shiell, A., \& Riley, T. (2009). Theorising interventions as events in systems. American Journal of Community Psychology, 43(3-4), 267-276.

Heller, K., Price, R. H., Reinharz, S., Riger, S., Wandersman, A., \& D'Aunno, T. A. (1984). Psychology and community change. Homewood, IL: Dorsey Press.

Herbertson, K., Ballesteros, A. R., Goodland, R., \& Munilla, I. (2009). Breaking ground: Engaging communities in extractive and infrastructure projects. Washington, DC: World Resources Institute.

Israel, B. A., Eng, E., Schulz, A. J., \& Parker, E. A. (2005). Methods in community-based participatory research for health. San Francisco, CA: Jossey-Bass.

Israel, B. A., Schulz, A. J., Parker, E. A., \& Becker, A. B. (2001). Community-based participatory research: Policy recommendations for promoting a partnership approach in health research. Education and Health (Abingdon), 14(2), 182-197.

Krug, E., Dahlberg, L. L., Mercy, J. A., Zwi, A. B., \& Lozano, R. (2002). World report on violence and health. Geneva, Switzerland: World Health Organization.

Laher, H. (2008). Religion and violence. Unpublished literature review, MRC-UNISA Safety and Peace Promotion Research Unit, Tygerberg, South Africa.

Lazarus, S., Duran, B., Caldwell, L., \& Bulbulia, S. (2012). Public health research and action: Reflections on challenges 
and possibilities of community-based participatory research. In J. Maddock (Ed.), Public Health. Intech (Open Access Publisher: www.intechweb.org).

Lazarus, S., Seedat, M., \& Naidoo, A. V. (2009, July). Mobilising religious health assets to build safe communities. Paper presented at African Religious Health Assets Programme (ARHAP) Conference, Cape Town, South Africa.

Lazarus, S., Tonsing, S., Ratele, K., \& Van Niekerk, A. (2011). Masculinity as a key risk and protective factor to male interpersonal violence: An exploratory and critical review. African Safety Promotion, 9(1), 23-50.

Mertens, D. M. (2005). Research and evaluation in education and psychology: Integrating diversity with quantitative, qualitative, and mixed methods (2nd ed.). Thousand Oaks, CA: Sage.

Minkler, M., \& Baden, A. C. (2008). Impacts of CBPR on academic researchers, research quality and methodology, and power relations. In M. Minkler \& N. Wallerstein (Eds.), Community-based participatory research for health: From process to outcomes (pp. 47-66). San Francisco, CA: Jossey-Bass.

Minkler, M., \& Wallerstein, N. (Eds.). (2008). Community-based participatory research for health: From process to outcomes (2nd ed.). San Francisco, CA: Jossey-Bass.

Nation, M., Bess, K., Voight, A., Perkins, D. D., \& Juarez, P. (2011). Levels of community engagement in youth violence prevention: The role of power in sustaining successful university-community partnerships. American Journal of Community Psychology, 48, 89-96.

Ortlipp, M. (2008). Keeping and using reflective journals in the qualitative research process. The Qualitative Report, 13(4), 695-705.

Popay, J. (2006). Community engagement and community development and health improvement: $A$ background paper for National Institute for Health and Clinical Excellence (NICE). Retrieved October 24, 2011 from antony.morgan@nice.org.uk

Ratele, K., \& Suffla, S. (2010). Men, masculinity and cultures of violence and peace in South Africa. In C. Blazina \& D. S. Shen-Miller (Eds.), An international psychology of men: Theoretical advances, case studies, and clinical innovations (pp. 27-55). New York, NY: Routledge.

Reason, P., \& Bradbury, H. (2008). The Sage handbook of action research: Participative inquiry and practice (2nd ed.). Thousand Oaks, CA: Sage.

Rifkin, S. B., Lewando-Hundt, G., \& Draper, A. K. (2000). Participatory approaches in health promotion and planning: $A$ literature review. London, England: Health Development Agency.

Schulz, A. J., Parker, E. A., Israel, B. A., Allen, A., Decarlo, M., \& Lockett, M. (2002). Addressing social determinants of health through community-based participatory research: The East Side Village Health Worker Partnership. Health Education Behaviour, 29(3), 326-341.

Smith, T. L. (2005). On tricky ground: Researching the native in the age of uncertainty. In N. K. Denzin \& Y. S. Lincoln (Eds.), The Sage handbook of qualitative research (3rd ed., pp. 85-107). Thousand Oaks, CA: Sage.

Springett, J., \& Wallerstein, N. (2008). Issues in participatory evaluation. In M. Minkler \& N. Wallerstein (Eds.), Community-based participatory research for health: From process to outcomes (pp. 404-418). San Francisco, CA: Jossey-Bass.

Stoeker, R. (2005). Research methods for community change: A project-based approach. Thousand Oaks, CA: Sage.

Wallerstein, N., \& Duran, B. (2008). The theoretical, historical, and practice roots of CBPR. In M. Minkler \& N. Wallerstein (Eds.), Community based participatory research for health (2nd ed., pp. 25-46). San Francisco, CA: Wiley.

\section{Endnotes}

${ }^{1}$ The authors do not agree with the use of apartheid racial terminology but, for research and redress purposes, utilise these terms so that realities relating to the legacy of apartheid are highlighted and understood.

${ }^{2}$ This project is also active in a South Memphis community, but this component is not included in this analysis of the research process. 